\title{
CONHECIMENTOS MOBILIZADOS A PARTIR DA CONSTRUÇÃO DO PROMPTUARIO DE JOHN NAPIER EM UM MINICURSO DE EXTENSÃO UNIVERSITÁRIA
}

\section{KNOWLEDGE MOBILIZED FROM THE CONSTRUCTION OF JOHN NAPIER'S PROMPTUARY IN A MINI-COURSE OF UNIVERSITY EXTENSION}

\author{
Pedro Henrique Sales Ribeiro ${ }^{1}$; Ana Carolina Costa Pereira ${ }^{2}$, Gisele Pereira Oliveira ${ }^{3}$
}

\begin{abstract}
RESUMO
A partir da tentativa de sanar alguns dos problemas que se fazem presentes no cenário educacional, em especial, na educação básica, muitas das universidades elaboram projetos e estratégias que visam ampliar a formação de docentes, seja a formação inicial ou a continuada. Dentre esses projetos, estão os cursos e minicursos de extensão universitária, que podem ser voltados para a docência. Nesse sentido, este estudo tem a intenção de apresentar alguns conceitos matemáticos, que foram mobilizados pelos cursistas durante o minicurso ministrado na XXV Semana Universitária, da Universidade Estadual do Ceará, no qual estudou-se o instrumento matemático para multiplicações, denominado Promptuario, presente na obra Rabdologiae, Seu Numerationis per Virgulas..., publicado em 1617 e de autoria de John Napier. Para tanto, valemonos da pesquisa participante no que se refere à aplicação do minicurso enquanto objeto de estudo, bem como utilizamos a pesquisa descritiva, em caráter qualitativo, além de estarmos amparados na proposta de interface entre história e ensino de Matemática. Alicerçados nisso, foi possível elencar e justificar os conhecimentos matemáticos que foram mencionados pelos cursistas nos relatórios de atividade e durante os encontros realizados, tanto aqueles que foram identificados tendo como base a leitura do documento original adotado quanto os que estavam sendo mobilizados durante o processo de construção física do Promptuario para multiplicação. Em suma, com a aplicação do minicurso, não só disponibilizamos novos conhecimentos e recursos para os discentes, como também compreendemos que esse instrumento pode ser incorporado em uma proposta de interface entre história e ensino de Matemática, a partir de uma vinculação do conhecimento matemático, que está presente na sua construção e utilização, junto ao processo histórico-contextual, em que esse conhecimento foi concebido.
\end{abstract}

\footnotetext{
${ }^{1}$ Graduando de Licenciatura em Matemática na Universidade Estadual do Ceará (UECE). Bolsista de Iniciação Científica e Tecnológica da Universidade Estadual do Ceará (UECE), Fortaleza, Ceará, Brasil. Endereço para correspondência: Av. Silas Munguba, 1700, Itaperi, Fortaleza, Ceará, Brasil, CEP: 60740903. E-mail: henrique.ribeiro@ aluno.uece.br.

ORCID iD: https://orcid.org/0000-0001-9270-5339.

${ }^{2}$ Pós-Doutora em Educação Matemática pela Pontifícia Universidade Católica de São Paulo (PUC-SP). Docente do programa de Pós-Graduação em Educação e do curso de Licenciatura em Matemática da Universidade Estadual do Ceará (UECE), Fortaleza, Ceará, Brasil. Endereço para correspondência: Av. Silas Munguba, 1700, Itaperi, Fortaleza, Ceará, Brasil, CEP: 60740-903. E-mail: carolina.pereira@ uece.br. (iD) ORCID iD: http://orcid.org/0000-0002-3819-2381.

${ }^{3}$ Doutoranda em Educação na Universidade Estadual do Ceará. Professora de Matemática da Secretaria de Educação do Estado do Ceará (SEDUC), Fortaleza, Ceará, Brasil. Endereço para correspondência: Av. Silas Munguba, 1700, Itaperi, Fortaleza, Ceará, Brasil, CEP: 60740-903. E-mail: giseleufc@ gmail.com.

(iD) ORCID iD: https://orcid.org/0000-0003-4044-3730.
} 
Palavras-chave: Promptuario para multiplicação; História da Matemática; Educação Matemática; Formação de Professores.

\begin{abstract}
From the attempt to solve some of the problems that are present in the educational scenario, especially in basic education, many of the universities develop projects and strategies that aim to expand the training of teachers, whether initial or continuing education. Among these projects, there are university extension courses and mini-courses, which can be geared towards teaching. In this sense, this study intends to present some mathematical concepts, which were mobilized by the course participants during the mini-course given at the XXV University Week, at the State University of Ceará, which studied the mathematical instrument for multiplication, called Promptuary, present in the work Rabdologiae, Seu Numerationis per Virgulas..., published in 1617 and authored by John Napier. For that, we used the participant research in what refers to the application of the short course as an object of study, as well as we use the descriptive research, in qualitative character, besides being supported in the proposal of interface between history and teaching of Mathematics. Based on this, it was possible to list and justify the mathematical knowledge that was mentioned by the course participants in the activity reports and during the meetings held, both those that were identified based on the reading of the original document adopted and those that were being mobilized during the process of physical construction of the Promptuario for multiplication. In short, with the application of the mini-course, we not only make new knowledge and resources available to students, but we also understand that this instrument can be incorporated into a proposal for an interface between history and teaching of Mathematics, based on a connection of mathematical knowledge, which is present in its construction and use, along with the historical-contextual process, in which this knowledge was conceived.
\end{abstract}

Keywords: Promptuary for multiplication; History of Mathematics; Mathematical Education Teacher training. 


\section{Introdução}

Dentre os mais variados problemas encontrados na educação básica, ressalta-se a existência de docentes com qualificações desatualizadas ou insuficientes para conseguirem acrescentar novos recursos didáticos no ambiente escolar. Apesar disso, “[...] essa preocupação não quer dizer reputar apenas ao professor e à sua formação a responsabilidade sobre o desempenho atual das redes de ensino" (GATTI, 2010, p.1359).

Como maneira de evitar que esse obstáculo aconteça, faz-se necessária uma boa formação inicial dos professores, bem como uma consistente formação continuada ao longo de toda a carreira de magistério. Nesse sentido, são traçadas diversas estratégias pelas universidades, para que se torne possível alcançar tal objetivo.

Essas estratégias são postas em prática de inúmeras formas no ambiente acadêmico, sendo uma dessas por meio de curso de extensão, uma atividade complementar e não obrigatória, que tem a intenção de permitir que os alunos ampliem seus conhecimentos acerca da sua área de atuação ou campo de estudo (CEARÁ, 2021).

Nesse contexto, ofertamos um minicurso de extensão durante a XXV Semana Universitária, da Universidade Estadual do Ceará (UECE), denominado “O processo de multiplicação por meio do instrumento de cálculo do século XVII, Promptuario, de John Napier", tendo seu enfoque nos discentes de Matemática, já que esse curso teve como objetivo uma abordagem voltada para a formação inicial de professores.

Assim, durante os dias em que o minicurso ocorreu, foram expostos os conteúdos relativos à construção física ${ }^{4}$ das varetas do Promptuario, sua graduação e sua utilização, tendo como base a proposta de construção da interface entre história e ensino de Matemática, que, para Saito e Dias (2013, p. 92), é a "“[...] constituição de um conjunto de ações e produções que promova a reflexão sobre o processo histórico da construção do conhecimento matemático para elaborar atividades didáticas que busquem articular história e ensino de matemática".

Para pautar essa proposta de interface, escolhemos um documento histórico original, um tratado do século XVII, que aborda a confecção e a utilização de três instrumentos matemáticos voltados para a realização de cálculos aritméticos, chamado

\footnotetext{
${ }^{4}$ Sobre esse tema, vide: Ribeiro, Cavalcante e Pereira (2020).
} 
Rabdologiae, seu Numerationis per Virgulas..., que foi escrito pelo matemático escocês John Napier (1550-1617) e publicado, em latim, no ano de 1617.

No entanto, a versão da qual nos valemos está disponível em língua inglesa, traduzida por William Frank Richardson, em 1990 e presente na obra de Rice, GonzálezVelasco e Corrigan (2017). Além disso, os excertos abordados, junto aos cursistas, foram uma tradução nossa para o português.

Entre esses três instrumentos abordados no tratado, está o Promptuario, um aparato desenvolvido por Napier, pelo qual é possível realizar cálculos extensos de multiplicação em um curto espaço de tempo, configurando-se como um instrumento que pode ter contribuído para o desenvolvimento do computador moderno (HAVIL, 2014), que corresponde a um aparato que tem, dentre suas diversas funções, a capacidade de efetuar cálculos em grande escala.

Dessa maneira, percebeu-se que explorar o processo de construção e de multiplicação existente no Promptuario, pautando-se no documento original e na proposta de interface entre história e ensino de Matemática, pode-se propiciar aos licenciandos a mobilização de conhecimentos, que podem contribuir para uma melhor formação inicial e, consequentemente, uma melhor atuação também no ensino básico.

Nesse sentido, pretendeu-se expor esses conceitos, que foram impulsionados a partir do procedimento de construção realizado pelos discentes e com base na manipulação do instrumento, tendo como embasamento as respostas dos cursistas nos respectivos relatórios de atividades, que foram disponibilizados.

\section{Acerca da metodologia}

Como forma de organizar o caminho percorrido para obter-se os resultados aqui presentes, iremos dividir a explanação relativa ao percurso metodológico em dois momentos, sendo o primeiro referente às questões envolvidas diretamente com a aplicação do curso e, em seguida, a respeito deste estudo apresentado.

Quanto ao minicurso, entendemos que, por se tratar de uma ferramenta que nos permitiu adquirir dados para embasar a pesquisa, ele está também atrelado a este estudo, podendo sua aplicação ser caracterizada como uma pesquisa participante, que, nas 
palavras de Prodanov e Freitas (2013, p. 67), é aquela que "se desenvolve a partir da interação entre pesquisadores e membros das situações investigadas”.

Para que fosse possível a coleta de dados mencionada, valemo-nos de alguns procedimentos expostos por Marconi e Lakatos (2003), como os formulários, os questionários e a observação, sendo esta última caracterizada como uma observaçãoparticipante, já que houve "a participação real do pesquisador com a comunidade ou grupo" (MARCONI; LAKATOS, 2003, p.194).

Assim, foi requerido aos participantes que preenchessem e assinassem o Termo de Concessão de Imagem e Som (TCIS), previsto pelo parecer consubstanciado do Conselho de Ética em Pesquisa (CEP), registrado sob o número 3.285.665, de forma que todos os cursistas estivessem cientes e autorizassem a reprodução, parcial ou completa, do que por eles foi dito durante o período e das imagens registradas.

Já no que se refere a este estudo, podemos, inicialmente, classificá-lo como uma pesquisa aplicada, se analisada a sua natureza, visto que "[...] tem como característica fundamental o interesse na aplicação, utilização e consequências práticas dos conhecimentos" (GIL, 2008, p.27). Também nos pautamos em uma abordagem qualitativa, isto é, aquela em que não se pode traduzir os materiais de pesquisa em números e necessita de uma interpretação dos fatos (PRODANOV; FREITAS, 2013).

Quanto aos seus objetivos, podemos definir este estudo como uma pesquisa descritiva, uma vez que, nessa tipificação, os pesquisadores visam apenas "descrever as características de determinada população ou fenômeno ou o estabelecimento de relações entre variáveis" (PRODANOV; FREITAS, 2013, p. 52). Por esse motivo, optamos por utilizar, como ferramenta de coleta de dados, os questionários, os relatórios de atividades e a observação.

\section{Sobre o minicurso}

Ministrado entre os dias 24 e 26 de novembro de 2020, na XXV Semana Universitária, da UECE, em especial, no X Encontro de Extensão, o minicurso "O processo de multiplicação por meio do instrumento de cálculo do século XVII, Promptuario, de John Napier" contou com uma carga horária de seis horas, além de ter 
sido realizado na modalidade a distância ${ }^{5}$ e valendo-se da plataforma de comunicação virtual Google Meet.

A aplicação desse minicurso visou, de maneira geral, explanar acerca dos aspectos históricos e matemáticos do instrumento Promptuario, bem como a sua construção e, principalmente, a sua utilização, que é voltada, especialmente, para a operação aritmética de multiplicação, além disso, como seu uso pode ser incorporado em uma proposta de interface entre história e ensino de Matemática, tendo foco na formação de professores.

Para tanto, as aulas ocorreram a partir de uma metodologia expositiva dialogada, já que foram aplicadas com base em "[...] uma exposição de conceitos, com a participação ativa dos alunos" (LOPES, 2012, p.30). A cooperação dos cursistas, por meio das interações via Chat ou mesmo na videoconferência, fez-se necessária para a categorização da aplicação do minicurso como uma pesquisa participante.

Por se tratar de uma atividade de extensão, todas as 30 vagas disponíveis, que foram totalmente preenchidas, foram ofertadas para o público geral, independentemente de serem ou não membros da universidade. No entanto, 29 dos inscritos têm algum vínculo com a instituição. A divulgação das referidas vagas foi realizada pelo próprio site da UECE, assim como pelo e-mail institucional vinculado a ela e por meio de postagens nas redes sociais.

Quanto ao método de avaliação, o único critério, para que o aluno fosse considerado aprovado e recebesse o certificado, referia-se às presenças nos encontros que ocorreram via Google Meet, sendo necessários, pelo menos, 2/3 de assiduidade nas aulas. Dessa forma, tivemos, entre os 30 alunos inscritos, um total de 20 aprovados, seguindo o critério de avaliação disposto anteriormente e, destes, tivemos 13 participantes que preencheram os formulários de coleta de dados, contribuindo, portanto, com os resultados apresentados, a partir das respostas dadas nos relatórios e questionários que foram disponibilizados.

Dos 13 alunos mencionados, é importante ressaltar que 11 deles são alunos do curso de Licenciatura em Matemática, um é discente do curso de Licenciatura em

\footnotetext{
${ }^{5}$ Devido à pandemia causada pelo Sars-Cov-2 (Coronavírus). Para mais informações, vide:
} https://coronavirus.saude.gov.br/. 
Pedagogia e o último é docente do curso de Licenciatura em Matemática, sendo todos vinculados à UECE.

Referente ao conteúdo programático planejado para o minicurso, estiveram presentes questões de caráter histórico-contextual em um primeiro momento; questões de ordem matemática, relativas à construção, no segundo momento; e utilização do instrumento, aplicada no terceiro e último momento, conforme disposto no Quadro 1.

Quadro 1 - Unidades e conteúdo do minicurso

\begin{tabular}{|c|c|c|c|}
\hline Unidade Temática & Conteúdo da Unidade & Atividades Desenvolvidas & CH \\
\hline $\begin{array}{l}\text { UNIDADE 1: } \\
\text { Conhecendo a } \\
\text { Matemática do } \\
\text { século XVII, o autor } \\
\text { e a obra. }\end{array}$ & $\begin{array}{l}\text { - Apresentação das matemáticas do } \\
\text { século XVII. } \\
\text { - Apresentação do autor. } \\
\text { - Apresentação do tratado. }\end{array}$ & $\begin{array}{l}\text { - Encontro via Google Meet. } \\
\text { - Questionário inicial. } \\
\text { - Avaliação do dia. }\end{array}$ & $2 \mathrm{~h}$ \\
\hline $\begin{array}{l}\text { UNIDADE 2: } \\
\text { Compreendendo o } \\
\text { processo de } \\
\text { construção do } \\
\text { instrumento. }\end{array}$ & $\begin{array}{l}\text { - Como construir o instrumento. } \\
\text { - Atividade de montagem do } \\
\text { instrumento. }\end{array}$ & $\begin{array}{l}\text { - Encontro via Google Meet. } \\
\text { - Atividade } 1 . \\
\text { - Relatório de atividade. } \\
\text { - Avaliação do dia. }\end{array}$ & $2 \mathrm{~h}$ \\
\hline $\begin{array}{l}\text { UNIDADE 3: } \\
\text { Efetuando operações } \\
\text { com o instrumento. }\end{array}$ & $\begin{array}{l}\text { - Como multiplicar utilizando o } \\
\text { Promptuario. } \\
\text { - Atividades de multiplicação. }\end{array}$ & $\begin{array}{l}\text { - Encontro via Google Meet. } \\
\text { - Atividade } 2 . \\
\text { - Relatório de atividade. } \\
\text { - Questionário final. }\end{array}$ & $2 \mathrm{~h}$ \\
\hline
\end{tabular}

Fonte: Elaborado pelos autores (2021).

A divisão em três unidades temáticas se deu por causa da carga horária e do total de dias, tendo como principal critério a progressão entre os conteúdos que foram apresentados. No primeiro dia, limitamo-nos a expor apenas conceitos históricos e contextuais que envolveram o tratado Rabdologiae, Seu Numerationis per Virgulas..., incluindo o status das matemáticas no século XVII e a biografia do autor. No segundo e terceiro dia, exploramos, de fato, o instrumento Promptuario, sendo um dia focado na construção e o seguinte na utilização.

Além disso, esses conteúdos, que foram dispostos em unidades, estiveram intimamente atrelados a alguns objetivos (Quadro 2), tanto para os docentes do curso quanto para os discentes. É importante ressaltar que tais objetivos foram delimitados visando uma melhor aplicação do minicurso, de forma que fossem entendidas as necessidades e intenções dos alunos que se inscreveram. 
Quadro 2 - Objetivos do minicurso

\begin{tabular}{|c|l|l|l|}
\hline Objetivos & \multicolumn{1}{|c|}{ Unidade 1 } & \multicolumn{1}{c|}{ Unidade 2 } & \multicolumn{1}{c|}{ Unidade 3 } \\
\hline Para o discente & $\begin{array}{l}\text { Entender e conhecer a } \\
\text { Matemática do século } \\
\text { XVII, autor da obra e o } \\
\text { próprio tratado. }\end{array}$ & $\begin{array}{l}\text { Compreender como } \\
\text { construir e manipular o } \\
\text { instrumento Promptuario. }\end{array}$ & $\begin{array}{l}\text { Conseguir efetuar a } \\
\text { operação de multiplicação } \\
\text { utilizando o instrumento }\end{array}$ \\
\hline Para o docente & $\begin{array}{l}\text { Conseguir explorar os } \\
\text { conhecimentos históricos } \\
\text { e contextuais do período. }\end{array}$ & $\begin{array}{l}\text { Expor o processo de de } \\
\text { construção, tal qual está } \\
\text { descrito pelo autor. }\end{array}$ & $\begin{array}{l}\text { Mostrar, com as palavras } \\
\text { do autor, como se dá a } \\
\text { utilização do instrumento, } \\
\text { para a operação de } \\
\text { multiplicação. }\end{array}$ \\
\hline
\end{tabular}

Fonte: Elaborado pelos autores (2021).

A partir do que foi mencionado pelos cursistas durante os encontros e valendonos das respostas deles nos questionários e relatórios disponibilizados, entendemos que os objetivos que estavam voltados para os discentes foram alcançados com êxito. Quanto aos que foram dispostos aos docentes, foi possível ter sucesso em relação ao que estava proposto, ainda que utilizando o meio remoto.

\section{Quanto aos conceitos mobilizados}

Durante os dois últimos dias de minicurso, aqueles em que a Matemática presente no instrumento Promptuario foi realmente abordada, foram apresentados aos alunos os conhecimentos contidos no texto original adotado, apoiando-se nas próprias palavras de Napier (2017), em uma versão traduzida do inglês para o português pelos próprios autores.

Dessa forma, com auxílio dos recursos de coleta de dados, que utilizamos, conseguimos compreender os conceitos matemáticos percebidos pelos alunos, tanto no que tange à Matemática que estava presente no próprio texto quanto aos que foram mobilizados durante o procedimento de construção do instrumento.

Ao analisar as respostas dadas para a pergunta: "Quais conhecimentos matemáticos você identificou a partir da leitura do texto?", no relatório de Atividade 1, referente ao encontro realizado no segundo dia de minicurso, conseguimos entender a percepção dos alunos quanto à forma como o autor do tratado descreve o processo de construção do Promptuario. Os conteúdos matemáticos, no texto, notados pelos cursistas, estão apresentados no Gráfico 1. 
Gráfico 1 - Conhecimentos identificados no texto

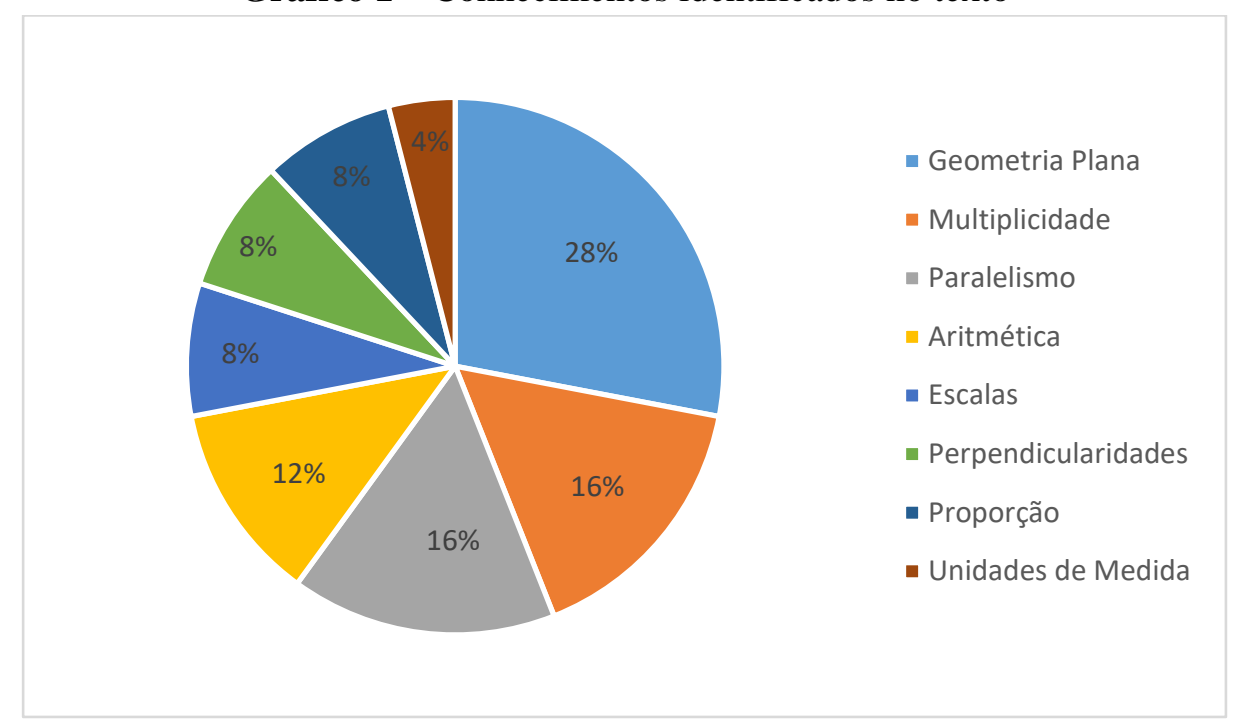

Fonte: Elaborado pelos autores (2021).

Embora a pergunta tenha sido direcionada a investigar os conceitos matemáticos que estavam presentes no texto, alguns participantes acabaram por apontar não um conceito, mas sim uma área de conhecimento, como "Geometria Plana" e "Aritmética", provavelmente, devido ao fato de que essa diferenciação é pouco difundida entre os alunos de Licenciatura em Matemática.

Assim, percebemos que o campo de conhecimento "Geometria Plana" teve o maior número de menções, já que o procedimento necessário para a construção, descrito por Napier (2017) em sua obra, aborda diversos conceitos geométricos, como no trecho: “[...] devem ser desenhadas linhas diagonais claras do ângulo inferior esquerdo para o ângulo superior direito de cada quadrado, dividindo cada quadrado ao meio para formar dois triângulos"6 (NAPIER, 2017, p. 714, tradução nossa), em que está envolvido, principalmente, o conhecimento de diagonal de um quadrado.

Em consonância a isso, observamos que, a partir da descrição do autor, os participantes do minicurso conseguiram localizar os conhecimentos matemáticos presentes e, assim, relacioná-los com os diferentes momentos do procedimento de construção. Dessa maneira, ressaltamos o que foi citado pelo Participante 3:

\footnotetext{
${ }^{6}$ Em inglês, lê-se: "should be drawn clear diagonal lines from the lower left to the upper right angle of each square, thus dividing each square in half toform two triangles" (NAPIER, 2017, p.714).
} 


\begin{abstract}
No momento que autor descreve que tem que dividir cada lado do quadrado maior em três pontos e ligar eles, notei que tem um conhecimento de perpendicularismo, já quando ele fala que é preciso dividir os nove quadrados em dois, traçando as diagonais, percebi a presença de vários conhecimentos geométricos, principalmente a questão do paralelismo.
\end{abstract}

Esses conceitos geométricos, que foram mencionados pelos cursistas, também estão compreendidos na Base Nacional Comum Curricular (BNCC), na unidade temática de Geometria, do $6^{\circ}$ ano, em que um de seus objetos de conhecimento é justamente a "Construção de retas paralelas e perpendiculares, fazendo uso de réguas, esquadros e softwares" (BRASIL, 2018).

Como consequência do processo de construção realizado pelos discentes, foi perceptível que alguns conhecimentos matemáticos emergiram e, para investigarmos quais foram esses conceitos, fizemos a seguinte pergunta, ainda no relatório de Atividade 1: "Quais conhecimentos matemáticos você mobilizou a partir da construção do instrumento?", de forma a buscar compreender como o Promptuario pode contribuir para a formação inicial e continuada de professores. As respostas estão no Gráfico 2.

Gráfico 2 - Conhecimentos identificados com base na construção

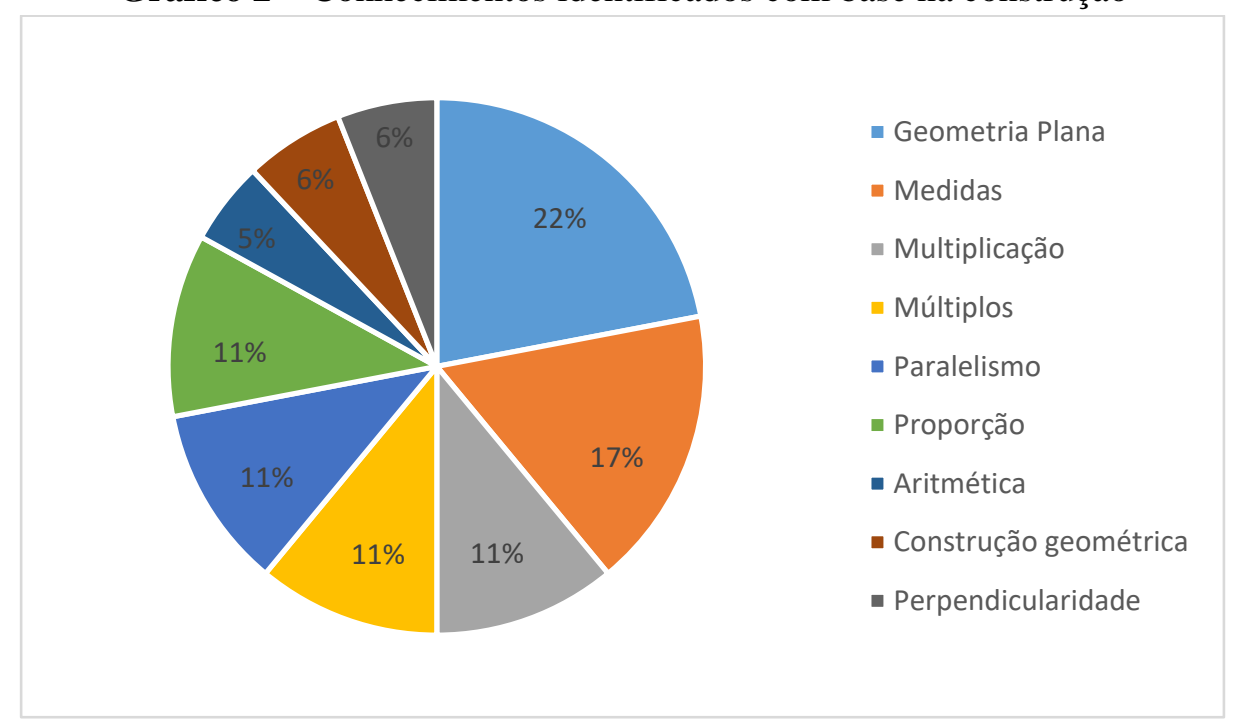

Fonte: Elaborado pelos autores (2021).

A área de conhecimento "Geometria Plana", do mesmo modo, teve grande destaque nas respostas desse questionamento, porém com menos ênfase do que anteriormente. Há dois principais motivos para essa diminuição: o primeiro é que, durante a descrição do autor, é possível notar onde estão inseridos os conhecimentos geométricos; 
já durante a construção, alguns conhecimentos são mobilizados, mas podem não ter sido percebidos pelos discentes.

O segundo provável motivo é a distinção que pode existir entre o conceito de "Geometria Plana", incluído no texto de maneira teórica e os conhecimentos de “Construção Geométrica", que são mais facilmente percebidos durante a tentativa prática de construção física do instrumento.

Nessas respostas, é notável que os conhecimentos de "multiplicação" e "multiplicidade" apareceram com grande destaque, pois, durante o processo de construção, na graduação do instrumento, a multiplicação está sempre presente, como, por exemplo, no trecho:

Nos locais que correspondem à letra b no triângulo esquerdo, escreva o algarismo à esquerda do número que é o dobro do que aparece na margem superior e, nos locais que correspondem à letra b no triângulo direito, escreva o algarismo à direita do mesmo número. Nos locais que correspondem à letra c à esquerda, inscreva o algarismo à esquerda do número que é três vezes o número na margem e, nos locais à direita, inscreva o algarismo. à direita do mesmo número (NAPIER, 2017, p. 715, tradução nossa) ${ }^{7}$.

Essas noções de multiplicações, que aparecerem no decorrer do processo de construção e, principalmente, na graduação do instrumento, também podem ser constatadas com o que foi dito pelos cursistas, segundo o Participante 6:

Na graduação, com relação aos múltiplos dos números, consegui perceber que um existe um grande conhecimento de multiplicação, já que ela envolve os conceitos de dobro, triplo e praticamente toda a tabuada de multiplicação, por que cada vareta vertical precisa de todos os múltiplos dela de 1 a 9.

$\mathrm{Na} \mathrm{BNCC}$, igualmente, podemos encontrar esses conceitos, visto que, na unidade temática de Números, do $6^{\circ}$ ano, um dos objetos de conhecimento é o de "Operações (adição, subtração, multiplicação, divisão e potenciação) com números naturais" (BRASIL, 2018), o que envolve diretamente os conceitos que foram mobilizados durante o procedimento de construção e de graduação do Promptuario.

\footnotetext{
${ }^{7}$ Em inglês, lê-se: "In the places that correspond to the letter $\mathrm{b}$ in the left triangle, write the lefthand figure of the number that is twice the one that appears in the upper margin, and in the places that correspond to the letter $b$ in the right triangle, write the right-hand figure of the same number. In the places which correspond to the letter $\mathrm{c}$ on the left, inscribe the left-hand figure of the number that is three times the number in the margin, and in the places on the right inscribe the right-hand figure of the same number" (NAPIER, 2017, p. 715).
} 
Comparando as respostas para cada uma das perguntas mencionadas anteriormente, foi possível notar que existe bastante semelhança entre os conhecimentos que os cursistas perceberam na leitura do tratado e os que foram mobilizados no processo de construção e de graduação do instrumento, o que revela a necessidade de que o texto histórico esteja sempre atrelado à atividade que está sendo desenvolvida.

Além do exposto, indagou-se em um questionário final: “Quais contribuições $o$ minicurso pôde deixar para sua formação?". A partir do que foi respondido, conseguiuse entender a importância dessa atividade de extensão universitária. Uma fala que ressalta esse fato é a da Participante 9, ela afirma que:

\footnotetext{
Como professora em formação, acredito que esse minicurso serviu para entender mais como funciona a junção da história com o ensino por meio de uma historiografia atualizada. O que me proporcionou um olhar mais crítico de como utilizar instrumentos providos dessa história e além disso trouxe conhecimentos sobre esse instrumento, que posso utilizar nas minhas futuras aulas.
}

Assim, com base em todas as respostas aqui analisadas, compreenderam-se alguns dos conhecimentos matemáticos que são mobilizados durante o processo de construção do Promptuario e como eles podem estar presentes dentro da formação de professores de Matemática, valendo-se de um recurso advindo da história da Matemática.

\section{Considerações Finais}

Com base no exposto, pode-se afirmar que as contribuições, que foram proporcionadas com o suporte do minicurso de extensão, para os cursistas, mostraram-se positivas, uma vez que elas acrescentaram novos conhecimentos aos alunos, favorecendo, principalmente, uma expansão do repositório de recursos didáticos, que estarão disponíveis para uma aplicação em sala de aula.

Ademais, como a abordagem empregada valorizou a interação alicerçada na obra Rabdologiae, Seu Numerationis per Virgulas..., os discentes conseguiram desenvolver certa proximidade com um texto histórico, já que, além da explanação inicial envolvendo o contexto do autor e da obra, em diversos momentos do curso, eles estiveram em contato direto com as palavras de Napier (2017).

Dessa forma, percebemos como a proposta de interface entre história e ensino de Matemática pode contribuir para a formação inicial e continuada de professores que 
ensinam Matemática, valendo-se de uma articulação que envolva tanto um conhecimento matemático quanto a maneira como esse conhecimento foi gradualmente construído em um contexto histórico.

\section{Agradecimentos}

Agradecemos à Universidade Estadual do Ceará, na figura de mantenedora da PróReitoria de Extensão (PROEX), por todo suporte que foi oferecido para a realização do minicurso, bem como ao Grupo de Pesquisas em Educação e História da Matemática (GPEHM), da UECE, por nos conceder a oportunidade de participar de discussões de grande importância para o amadurecimento desta e de outras pesquisas.

\section{Referências}

BRASIL. Base Nacional Comum Curricular. Brasília: MEC, 2018. Disponível em: http://basenacionalcomum.mec.gov.br/abase/. Acesso em: 25 fev. 2021.

CEARÁ. Universidade Estadual do Ceará. Secretaria Estadual de Educação. O que é um curso de Extensão. 2021. Disponível em: http://www.uece.br/proex/cursos-deextensao/o-que-e-um-curso-de-extensao/. Acesso em: 05 fev. 2021.

GATTI, Bernardete Angelina. Formação de professores no Brasil: características e problemas. Educ. Soc., Campinas, v. 31, n. 113, p. 1355-1379, Dec. 2010. Disponível em: https://www.scielo.br/pdf/es/v31n113/16.pdf. Acesso em 05 fev. 2021. https://doi.org/10.1590/S0101-73302010000400016

GIL, Antônio Carlos. Como elaborar projetos de pesquisa. 6 ed. São Paulo: Atlas, 2008.

HAVIL, Julian. John Napier: Life, Logarithms, and Legacy. New Jersey: Princeton University Press, 2014.

LOPES, Tania Oliveira. Aula expositiva dialogada e aula simulada: comparação entre estratégias de ensino na graduação em enfermagem. 2012. 125 f. Dissertação (Mestrado) - Curso de Enfermagem, Universidade de São Paulo, São Paulo, 2012.

MARCONI, Marina de Andrade; LAKATOS, Eva Maria. Fundamentos de Metodologia Científica. 5. ed. São Paulo: Atlas S.A, 2003. 311 p.

NAPIER, John. Rabdologiae, Seu Numerationis Per Virgulas: cum appendice de expeditíssimo Multiplicationes promptuario, quibus acessit e arithmeticea localis liber unus. In: RICE, Brian.; GONZÁLEZ-VELASCO, Enrique.; CORRIGAN, Alexander. The Life and Works of John Napier. Cham: Springer, 2017. p. 652-749. 
PRODANOV, Cleber Cristiano; FREITAS, Ernani César de. Metodologia do

Trabalho Científico: Métodos e Técnicas da Pesquisa e do Trabalho Acadêmico. 2. ed. Novo Hamburgo: Editora Feevale, 2013. 277 p.

RIBEIRO, Pedro Henrique Sales.; CAVALCANTE, Davi Souza.; PEREIRA, Ana Carolina Costa. O Procedimento de Construção das Varetas do Promptuario de John Napier (1550-1617). Boletim Cearense de Educação e História da Matemática, v. 7, n. 21, p. 112-121, 10 dez. 2020.

SAITO, Fumikazu; DIAS, Marisa da Silva. Interface entre história da Matemática e ensino: uma atividade desenvolvida com base num documento do século XVI. Ciênc. educ. (Bauru), Bauru, v. 19, n. 1, p. 89-111, 2013. Disponível em:

https://www.scielo.br/pdf/ciedu/v19n1/07.pdf. Acesso em 05 fev. 2021. https://doi.org/10.1590/S1516-73132013000100007.

Recebido em: 04 / 03 / 2021 Aprovado em: 14 / 04 / 2021 